\title{
Exclusive contracts and market dominance
}

\author{
By Giacomo Calzolari and Vincenzo Denicolö*
}

\begin{abstract}
We propose a new theory of exclusive dealing. The theory is based on the assumption that a dominant firm has a competitive advantage over its rivals, and that the buyers' willingness to pay for the product is private information. In this setting, the dominant firm can impose contractual restrictions on buyers without necessarily compensating them, implying that exclusive dealing contracts can be both profitable and anticompetitive. We discuss the general implications of the theory for competition policy and illustrate by examples its applicability to antitrust cases.

JEL: D42 , D82 , L42

Keywords: Exclusive dealing, Non-linear pricing, Antitrust, Competition Policy
\end{abstract}

Exclusive dealing contracts have long raised antitrust concerns. However, existing anticompetitive theories are not entirely satisfactory since their assumptions do not always fit real antitrust cases. In this paper, we propose a new theory of competitive harm, which is arguably more broadly applicable than existing ones. We illustrate the applicability of the theory by examples and discuss its more general implications for competition policy.

Our analysis centers around a simple anticompetitive story. Two or more firms are active in an industry and compete by supplying substitute goods. By contractually restricting buyers' purchases from its competitors, so the story goes, one firm can raise both its market share and its prices. This increases the firm's profits at the expense of buyers and rivals alike.

This story is intuitive, easy to understand, and probably relevant to many antitrust cases. However, it is difficult to reproduce in rigorous models. One major obstacle is the so-called Chicago critique. This critique holds, firstly, that buyers must be compensated for accepting exclusive deals, and secondly, that rivals may respond by offering similar contracts. This, according to the critics, undermines the profitability of exclusive contracts.

We overcome this critique by making two simple, often realistic, assumptions. The

* Calzolari: Department of Economics, University of Bologna, Piazza Scaravilli 2, 40126 Bologna, Italy (e-mail: giacomo.calzolari@unibo.it) and CEPR; Denicolò: Department of Economics, University of Bologna, Piazza Scaravilli 2, 40126 Bologna, Italy (e-mail: vincenzo.denicolo@unibo.it), University of Leicester and CEPR. We are most grateful to three anonymous referees and a coeditor for many detailed comments that greatly improved the paper. We also thank Subir Bose, Chiara Fumagalli, Glenn Ellison, Sjaak Hurkens, Doh-Shin Jeon, Volker Nocke, Paolo Ramezzana, Emanuele Tarantino, Helen Weeds, Chris Wallace, Mike Whinston, Piercarlo Zanchettin and seminar participants at MIT, Boston College, Tilburg (TILEC), Madrid (CEMFI), Barcelona Summer Forum 2015, Bologna, Boston University, Cattolica Milan, Essex, Leicester, Stavanger, Rochester, Pittsburgh, Bocconi, University of Washington, the Economics of Con ict and Cooperation workshop at Bergamo, the SAET conference in Paris, the IIOC conference in Chicago, the CEPR applied industrial organization conference in Athens, the US DoJ, and the European Commission (DG Comp) for useful discussion and comments. The usual disclaimer applies. The authors declare that they have no relevant or material financial interests that relate to the research described in this paper. 
first is that firms cannot fully extract the buyers' surplus, for the simple reason that they do not know exactly how large it is. In other words, the buyers' willingness to pay for the product is private information. The second assumption is that one firm stands out from the others, holding a dominant position. ${ }^{1}$

By itself, dominance is benign in our model: it arises because the dominant firm enjoys a competitive advantage over its rivals, in terms of higher quality, lower costs, or a combination of the two. However, we show that if the competitive advantage is large enough, it allows the dominant firm to use exclusive contracts for anticompetitive purposes. The intuition for this is as follows. Buyers obtain information rents even if they deal exclusively with the dominant firm. When the competitive advantage is large, such rents may be greater than the surplus that buyers could obtain by trading exclusively with the dominant firm's competitors. This may be true even if the dominant firm charges monopoly prices while its competitors price at cost. In this case, the dominant firm can impose exclusivity without compensating the buyers, and rivals cannot respond. This argument completely overcomes the Chicago critique: in fact, exclusive contracts can render the dominant firm totally immune from competition.

This anticompetitive mechanism is better understood if one considers that in cases where exclusive contracts are banned, firms are forced to compete for each marginal unit of a buyer's demand. Excluding rivals thus requires a limit pricing strategy, which in turn entails a sacrifice of profits. When exclusive contracts are permitted, on the other hand, firms compete for the entire volume demanded by a buyer - i.e., competition is in "utility space." In utility space, the dominant firm can exclude rivals by leveraging on the information rents left on inframarginal units. If the competitive advantage is large, the dominant firm can keep charging monopoly prices and exclude rivals by means of exclusivity clauses only. If the competitive advantage is more limited exclusive prices cannot be set at the monopoly level, but the discount required to foreclose is smaller than it would be in the absence of exclusive contracts.

However, one further difficulty remains when considering this intuitive explanation. As O'Brien and Shaffer (1997) and Bernheim and Whinston (1998) have shown, in common agency models of complete information the total surplus from trade is necessarily maximised in equilibrium. ${ }^{3}$ This implies that if foreclosure is inefficient, e.g. because rivals supply imperfect substitutes for which there is demand, the dominant firm will not

\footnotetext{
${ }^{1}$ Besides often being true, this case is certainly of relevance for antitrust policy. The vast majority of antitrust cases involve dominant firms that control a substantial share of the market in the face of smaller rivals. In fact, some degree of asymmetry may be a prerequisite for competition policy intervention. For example, violation of Section 2 of the Sherman Act requires "the possession of monopoly power in the relevant market" (United States v. Grinnel Corp.). Likewise, infringement of Article 102 of the Treaty of Rome, i.e. the abuse of a dominant position, obviously requires that a firm actually enjoys a dominant position.

${ }^{2}$ The notion of competition in utility space was introduced by Bliss (1988) and used by Armstrong and Vickers (2001) and Rochet and Stole (2002), among others. These authors focus on models of one-stop shopping where exclusivity is not imposed contractually but arises for technological reasons.

${ }^{3}$ The intuition is simple. Under complete information a firm would use non-linear pricing to extract all the surplus in excess of what the buyer can obtain by trading with the firm's competitors (which supply substitute goods). Consequently, the firm would offer a contract that maximises such surplus - a property known as bilateral efficiency. In the absence of contractual externalities, under mild regularity conditions such bilateral efficiency conditions would result in global efficiency. O'Brien and Shaffer (1997) also highlight the fact that the surplus from trade is maximised even if buyers possess a certain bargaining power, as long as bargaining is efficient.
} 
want to foreclose rivals. If instead foreclosure is efficient, it can be achieved even with simple non-linear pricing. Thus, exclusive contracts cannot be profitable: at best, they are redundant.

However, this neutrality does not apply to our setting because the dominant firm does not exactly know the buyers' willingness to pay and hence cannot fully extract the surplus. As is well known, it is then profitable to distort the contracts that apply in certain states of demand in order to extract more surplus in others. When contracts cannot be conditioned on rivals' volumes, the optimal distortion is the standard one, i.e., to reduce own sales below the efficient level. This entails sacrificing profits, however. With exclusive contracts, on the other hand, a firm can reduce its rivals' volumes. Like the standard distortion, this makes these contracts less attractive, reducing buyers' rents in other states of demand. However, the distortion is now directly profitable for the dominant firm, as the products are substitutes.

Since with exclusive contracts the distortion is more profitable, more distortion is created. This implies that when the dominant firm's competitive advantage is large, exclusive dealing contracts are profitable and anticompetitive. They harm the buyers, who suffer from stronger distortion, and the rivals, who have to absorb a large part of this distortion.

When the competitive advantage is small, however, a countervailing effect may come into play. Whereas product differentiation softens competition for marginal units, it does not soften competition in utility space. In utility space, product diversity is in fact irrelevant: all that counts is the amount of rent left to buyers. When firms are relatively symmetric, this tends to make competition in utility space tougher than competition for marginal units.

This procompetitive effect is the focus of Calzolari and Denicolò (2013). That paper studies a symmetric duopoly where no firm has any competitive advantage over the other. The anticompetitive mechanism analysed here, which crucially hinges on firms' asymmetry, would be mute if firms were symmetric. Each firm would still have a unilateral incentive to offer exclusive contracts so as to try and force the rival to absorb the distortion. But then the firms would be caught in a prisoners' dilemma and end up competing in utility space, where they are perfectly homogeneous. Price competition would then become extremely intense, implying that exclusive contracts would reduce prices and profits. $^{4}$

To abstract from this procompetitive effect, most of this paper analyses the case in which the dominant firm faces a competitive fringe. The fringe always prices at cost and thus the intensity of competition cannot be further enhanced. This allows us to focus on the new anticompetitive mechanism central to this paper. However, we also consider the case of a duopoly where the dominant firm faces a smaller, less efficient competitor which enjoys a degree of market power. This brings the procompetitive effect into the picture: the anticompetitive effect prevails when the competitive advantage is large, the

\footnotetext{
${ }^{4}$ Calzolari and Denicolò (2013) then go on to argue that firms can coordinate their pricing strategies to some extent so as to relax competition. However, in a non-cooperative equilibrium the scope for coordination is limited and so the final effect of exclusive contracts is to enhance competition.
} 
procompetitive effect when it is small.

In the last part of the paper, we discuss the empirical predictions of the theory. The theory naturally applies to situations where a dominant firm controls a substantial share of the market and competes with a smaller, but already active, rival (or group of rivals). A recent antitrust case that fits this description is the Intel case. From 2001 to 2007, Intel allegedly used various types of loyalty discounts for anticompetitive purposes. Over the period in question, Intel had a market share of more than $80 \%$, while its strongest competitor, AMD, controlled a mere $15 \%$ of the market. We use this example to illustrate the kind of empirical evidence that may substantiate, or falsify, our theory. It seems that the theory fits this case quite well.

We end this introduction by brie y reviewing some related literature. After presenting our main results, a fuller discussion of the literature is offered in Section IV. Much of the literature regarding the possible anticompetitive effects of exclusive contracts, focuses on the case of complete information and avoids the neutrality result mentioned above that the scope for negotiation is limited, which results in contractual externalities. Contractual externalities typically arise when the scope for negotiation is limited. For example, a potential entrant may not be able to contract with the buyers until after they have been signed up by the incumbent, as in Aghion and Bolton (1987), Rasmusen, Ramseyer and Wiley (1991) and Segal and Whinston (2000). Or firms may be unable to contract with buyers due to enter the market only at a later date, as in Bernheim and Whinston (1998, sect. IV). Contractual externalities may also arise when buyers compete in downstream markets, as in Asker and Bar-Isaac (2014). In some models, both mechanisms are simultaneously at work (see e.g. Fumagalli and Motta, 2006; Simpson and Wickelgren, 2007; Wright, 2009; Johnson, 2012).

In this paper we pursue a different line of inquiry, where the non-neutrality of exclusive contracts is due to the difficulty of extracting the buyers' rent. In an earlier paper, Mathewson and Winter (1987) assumed that surplus extraction is imperfect because firms are restricted to linear pricing. However, in their complete information setting two-part tariffs would restore neutrality. With adverse selection, on the contrary, surplus extraction is imperfect even if firms are not restricted to simple contracts. The adverse selection approach has been pioneered by Martimort (1996), who posits symmetric firms and models exclusive dealing by assuming that each firm has access to a different retailer. Unfortunately, these assumptions effectively rule out competition for exclusives and the possibility of foreclosure outcomes. Majumdar and Shaffer (2009) are closer in spirit to our own approach. However, they focus on market-share discounts and posit that demand may only take on two possible values.

The rest of the paper proceeds as follows. After setting out the model in Section I, Section II focuses on the baseline case in which the dominant firm faces a competitive fringe. Section III brie y analyses the case of duopoly, and the case in which the dominant firm's competitive advantage is relatively stronger when demand is high rather than when it is low, as in the baseline model. Section IV illustrates the applicability of the theory to real antitrust cases, contrasting ours with alternative explanations. Finally, Section V summarises the main arguments, discusses broader implications for competition 
policy, and hints at some possible directions for future research.

\section{Model}

We consider a one-period model of price competition. There are two substitute goods, $A$ and $B$. Good $A$ is supplied by firm $A$. In our baseline model we assume that good $B$ is supplied by a competitive fringe. The case in which good $B$ is supplied by firm $B$ (the duopoly model) is presented in Section III.

A buyer who buys $q_{A}$ units of good $A$ and $q_{B}$ units of good $B$ obtains a benefit, measured in monetary terms, of $u\left(q_{A}, q_{B}, \theta\right)$. We may think of the buyer as a downstream firm, with $u$ as its gross profits, ${ }^{5}$ or as a final consumer, with $u$ as his utility function. The function $u$ is symmetric, smooth and concave in quantities. It initially increases in $q_{A}$ and $q_{B}$, but in view of our normalisation of costs (see below) we assume that there exists a finite "satiation" point. The goods are imperfect substitutes, in the sense that $0>u_{q_{i} q_{j}}\left(q_{A}, q_{B}, \theta\right)>u_{q_{i} q_{i}}\left(q_{A}, q_{B}, \theta\right)$, where subscripts denote partial derivatives. This implies that the buyer has a preference for variety. The reservation payoff, $u(0,0, \theta)$, is normalised to zero.

The one-dimensional parameter $\theta$ is the buyer's private information; it is distributed over an interval $\left[\theta_{\min }, \theta_{\max }\right]$ according to a distribution function $F(\theta)$ with density $f(\theta)$. We assume that higher values of $\theta$ correspond to higher demand and we make the singlecrossing assumption $u_{\theta q_{i}}\left(q_{A}, q_{B}, \theta\right) \geq 0$.

We assume that firm $A$ (the dominant firm) has a competitive advantage in terms of lower costs, better quality, or a combination of the two. Firm A's marginal production cost is normalised to zero. When firm $A$ has a competitive advantage in terms of costs, the unit production cost of product $B$ is $c \geq 0 .{ }^{6}$ When the competitive advantage is in terms of quality, instead, it is captured by writing the buyer's payoff as $u\left(q_{A}, q_{B}, \theta\right)-c q_{B}$ (with $B$ 's cost now set at zero). In this case, parameter $c$ can be interpreted as an index of vertical product differentiation, with product $A$ being of better quality, and hence in greater demand, than product $B$. The two formulations are analytically equivalent, and to fix ideas in what follows we shall stick to the cost interpretation.

To make the analysis interesting, we assume that total exclusion is inefficient. In this setting, this requires that $q_{B}^{f b}\left(\theta_{\max }\right)>0$, where

$$
\left\{q_{A}^{f b}(\theta), q_{B}^{f b}(\theta)\right\}=\arg \max _{q_{A}, q_{B}}\left[u\left(q_{A}, q_{B}, \theta\right)-c q_{B}\right]
$$

are the full information, first best quantities. This condition places an upper bound on c. To simplify the exposition, we assume that the market is uncovered. A sufficient

\footnotetext{
${ }^{5}$ In this interpretation, our analysis literally requires that downstream firms operate in separate markets and do not interact strategically with each other. Otherwise, contractual externalities might arise, as discussed above. However, our insights also apply to situations in which downstream firms do in fact compete, as long as they have a certain degree of market power.

${ }^{6}$ We abstract from fixed costs, and hence from economies of scale. As long as all firms remain active, this entails no loss of generality. Furthermore, in the competitive fringe model one can interpret $c$ as the minimum average cost of a number of identical firms, thus allowing for economies of scale at firm level.
} 
condition for this is that $q_{A}^{f b}\left(\theta_{\min }\right)=0$ and $q_{A}^{f b}(\theta)>0$ for all $\theta>\theta_{\text {min. }}{ }^{7}$

Firms compete by simultaneously and independently offering menus of contracts. We distinguish two different modes of competition according to the type of contract that the firms may offer. With simple non-linear pricing, the payment to each firm depends only on its own quantity. A strategy for firm $i$ is thus a function $P_{i}\left(q_{i}\right)$ in which $q_{i}$ is the quantity firm $i$ is willing to supply, and $P_{i}\left(q_{i}\right)$ is the corresponding total payment it asks for. With exclusive contracts, a strategy for firm $i$ comprises two price schedules, $P_{i}^{E}\left(q_{i}\right)$ and $P_{i}^{N E}\left(q_{i}\right)$. The former applies to exclusive contracts $\left(q_{j}=0\right)$, the latter to non exclusive ones $\left(q_{j}>0\right){ }^{8,9}$

The buyer observes the firms' offers and the realisation of demand $\theta$ and then chooses the quantities $\left\{q_{A}(\theta), q_{B}(\theta)\right\}$ that maximise his net payoff. The buyer has no bargaining power, but is large enough that firms can monitor whether he purchases from their competitors. To avoid any issues of equilibrium existence when firms compete for exclusives, we assume that if the buyer is indifferent between firm $A$ 's offer and the best alternative, then he trades with firm $A$. We focus on subgame perfect equilibria, ruling out equilibria that rely on weakly dominated strategies.

Further regularity conditions, which serve to simplify the analysis, are set out in the Appendix. An example that satisfies all of our conditions is the uniform-quadratic model, in which the parameter $\theta$ is assumed to be uniformly distributed over the interval $[0,1]$ and the buyer's payoff is taken to be:

$$
u\left(q_{A}, q_{B}, \theta\right)=\theta\left(q_{A}+q_{B}\right)-\frac{1-\gamma}{2}\left(q_{A}^{2}+q_{B}^{2}\right)-\gamma q_{A} q_{B} \cdot{ }^{10}
$$

With this specification, the equilibrium quantity schedules are piecewise linear, and the equilibrium price schedules are piecewise quadratic. ${ }^{11}$

\footnotetext{
${ }^{7}$ In fact it suffices that there exists a $\theta \in\left[\theta_{\min }, \theta_{\max }\right]$ such that $q_{A}^{f b}(\theta)=0$. If this holds, one can always choose $\theta_{\text {min }}$ as the largest $\theta$ for which $q_{A}^{f b}(\theta)=0$ and re-scale the distribution function accordingly.

${ }^{8}$ To guarantee a solution to the buyer's maximisation problem, we assume that each price schedule $P_{i}$ must be non decreasing in $q_{i}$ (a free disposal assumption which also implies that price schedules must be differentiable almost everywhere), that it satisfies $P_{i}(0)=0$, and that it is upper semi-continuous.

${ }^{9}$ In section 5 of the online Appendix, we also allow for market-share contracts, whereby a firm can more freely condition its payment request on its competitors' sales volume: $P_{i}=P_{i}\left(q_{i}, q_{j}\right)$.

${ }^{10}$ When buyers are final consumers, (2) implies that under linear pricing the demand functions would be:

$$
p_{i}=\theta-(1-\gamma) q_{i}-\gamma q_{j} .
$$
}

If, on the contrary, buyers are downstream firms, assuming that such firms are local monopolies and are restricted to linear pricing, and normalising their costs to zero, (2) is the downstream profit function associated with the following demand functions for the final products:

$$
p_{i}=\theta-\frac{1-\gamma}{2} q_{i}-\frac{\gamma}{2} q_{j}
$$

In both cases, the parameter $\gamma$ represents the degree of substitutability among the products: it ranges from $\frac{1}{2}$ (perfect substitutes) to 0 (independent goods). The assumed relationship between own and cross price effects on demand serves only to guarantee that changes in $\gamma$ do not affect the size of the market. As Shubik and Levitan (1980) have argued, this rules out spurious effects in the comparative statics analysis.

${ }^{11}$ The explicit solutions for this case are reported in the online Appendix (section 2). 


\section{Equilibrium}

In this section, we present the model's equilibrium and discuss its qualitative properties.

\section{A. Results}

We start by characterising the model's equilibrium, both with and without exclusive contracts. Clearly, the competitive fringe will always price at cost (i.e., $\left.P_{B}\left(q_{B}\right)=c q_{B}\right)$. Given this passive behaviour, finding the model's equilibrium is tantamount to finding the dominant firm's optimal strategy.

As it turns out, with non-linear pricing the dominant firm simply uses combinations of the following strategies:

(i) Monopoly: $P^{m}(q)$ and $q^{m}(\theta) .{ }^{12}$ This is the outcome that would prevail if product $B$ were not supplied at all. The price schedule $P^{m}(q)$ is the solution to the standard monopolistic non-linear pricing problem, which is obtained by simply setting $q_{B}=0$ in the buyer's payoff function $u\left(q_{A}, q_{B}, \theta\right)$.

(ii) Limit pricing: $P^{\lim }(q)$ and $q^{\lim }(\theta)$. The "limit pricing" quantity $q^{\lim }(\theta)$ is implicitly defined by the condition

$$
u_{q_{B}}\left(q_{A}, 0, \theta\right)=c .
$$

By supplying $q^{\lim }(\theta)$, the dominant firm forecloses the competitive fringe even without any exclusive dealing arrangements. (Proving that $q^{\lim }(\theta)$ is monotone, and hence implementable by a price schedule $P^{\lim }(q)$, is a straightforward matter.)

(iii) Common representation: $P_{A}^{c r}(q)$ and $q_{A}^{c r}(\theta)$. Whereas the first two strategies require, or imply, that $q_{B}=0$, in this case the dominant firm accommodates the fringe. Therefore, it must now account for the fact that buyers purchase a substitute product. The equilibrium quantity $q_{A}^{c r}(\theta)$ is still obtained as the solution to a problem of "monopolistic" non-linear pricing, but buyers now behave as if they had an "indirect" payoff function

$$
v\left(q_{A}, \theta\right)=\max _{q_{B}}\left[u\left(q_{A}, q_{B}, \theta\right)-P_{B}\left(q_{B}\right)\right],
$$

which is the maximum payoff that can be obtained in state $\theta$ by purchasing $q_{A}$ and then trading optimally with the fringe. (The indirect payoff function is similar to residual demand in models of linear pricing.) Given $q_{A}^{c r}(\theta)$, the equilibrium quantity of product $B$ is

$$
q_{B}^{c r}(\theta)=\arg \max _{q_{B}}\left[u\left(q_{A}^{c r}(\theta), q_{B}, \theta\right)-P_{B}\left(q_{B}\right)\right] .
$$

\footnotetext{
${ }^{12}$ Note that for any quantity schedule $q(\theta)$, the price schedule that implements it is only defined modulo a constant term. However, when the market is uncovered the marginal buyer's demand is negligible. Hence, the price schedules which apply to the marginal buyer cannot involve any fixed fee or subsidy - a property first noted by Wilson (1993). (The marginal buyer is the lowest type purchasing a positive quantity of the good.) In contrast, the price schedules that apply to non-marginal buyers may involve constant terms, which are specified below.
} 
The derivation of these schedules is illustrated in greater detail in the Appendix.

We are now ready to state the characterisation results. Readers who are not interested in analytical details may proceed directly to Subsection II.B below.

Non-linear pricing equilibrium. The characterisation of the non-linear pricing equilibrium is simplest if one rules out bunching (thereby ensuring that $q^{m}(\theta)$ and $q_{A}^{c r}(\theta)$ are strictly monotone) as well as multiple intersections between the curve $q^{\lim }(\theta)$ and the curves $q^{m}(\theta)$ and $q_{A}^{c r}(\theta)$. The Appendix formally states these assumptions. While they are not really necessary for our results, they simplify the exposition considerably.

Define $c^{m}$ as the lowest $c$ such that there exists at least one state of demand $\theta$ for which $q^{m}(\theta)>q^{\lim }(\theta)$, and $c^{\lim }$ as the lowest $c$ such that there exists at least one state of demand $\theta$ for which $q_{A}^{c r}(\theta)>q^{\lim }(\theta) .{ }^{13}$ We then have (proofs may be found in the online Appendix)

PROPOSITION 1: With non-linear pricing, there is a unique equilibrium:

- when $0 \leq c \leq c^{\text {lim }}$, firm A offers the price schedule

$$
P_{A}(q)=P_{A}^{c r}(q)
$$

- when $c^{\lim } \leq c \leq c^{m}$, firm A offers the price schedule

$$
P_{A}(q)= \begin{cases}P^{\lim }(q) & \text { for } 0 \leq q \leq q^{\lim }\left(\breve{\theta}_{B}\right) \\ P_{A}^{c r}(q)+\text { constant } & \text { for } q \geq q^{\lim }\left(\breve{\theta}_{B}\right),\end{cases}
$$

where $\breve{\theta}_{B}$ is the highest $\theta$ such that $q_{B}^{c r}(\theta)=0$ and the constant guarantees the continuity of the price schedule;

- when $c \geq c^{m}$, firm A offers the price schedule

$$
P_{A}(q)= \begin{cases}P^{m}(q) & \text { for } 0 \leq q \leq q^{m}\left(\theta^{\lim }\right) \\ P^{\lim }(q)+\text { constant } & \text { for } q^{m}\left(\theta^{\lim }\right) \leq q \leq q^{\lim }\left(\breve{\theta}_{B}\right) \\ P_{A}^{c r}(q)+\text { constant } & \text { for } q \geq q^{\lim }\left(\breve{\theta}_{B}\right),\end{cases}
$$

where $\theta^{\lim }$ is the solution to $q^{m}(\theta)=q^{\lim }(\theta)$ and the constants guarantee the continuity of the price schedule.

Equilibrium with exclusive contracts. When exclusive contracts are permitted, the dominant firm can offer two distinct price schedules, $P_{A}^{E}\left(q_{A}\right)$ and $P_{A}^{N E}\left(q_{A}\right)$. Accordingly, the buyer may sign a non-exclusive contract in some states of demand, and an exclusive contract in others.

\footnotetext{
${ }^{13}$ The existence of these thresholds is guaranteed as $q^{\lim }(\theta)$ decreases with $c$ and vanishes if $c$ is large enough, $q_{A}^{c r}(\theta)$ increases with $c$, and $q^{m}(\theta)$ is independent of $c$. The fact that $q^{m}(\theta)$ satisfies the no-distortion-at-the-top property (conditional on $q_{B}=0$ ) ensures that $c^{m}$ is lower than the upper bound on $c$ implied by the condition that $q_{B}^{f b}\left(\theta_{\max }\right)>0$. That $c^{m}>c^{\lim }$ is shown in the proof of Proposition 1.
} 
This results in a "hybrid" pricing problem in which contracts are effectively conditional upon both a continuous variable (i.e. $q_{A}(\theta)$ ) and a discrete variable, which is whether $q_{B}(\theta)$ can be positive or must be nil. The solution exhibits the following separation property (Calzolari and Denicolò, 2015): when the firm can offer both exclusive and non-exclusive contracts, the non-exclusive prices $P_{A}^{N E}\left(q_{A}\right)$ must be the same (except possibly for a fixed fee or subsidy) as if the dominant firm were constrained to offer non-exclusive contracts only. Likewise, the exclusive prices $P_{A}^{E}\left(q_{A}\right)$ must be the same (again, modulo a constant) as if the dominant firm were constrained to offer exclusive contracts only.

This implies that the schedule $P_{A}^{N E}\left(q_{A}\right)$ coincides with the price schedule characterised in Proposition 1, plus a constant term. As for $P_{A}^{E}$, consider the constrained problem in which the dominant firm can only contract under exclusivity. In this case, the dominant firm competes with the fringe in utility space, where the products are effectively homogeneous. As a result, the dominant firm either charges the monopoly prices or else undercuts the fringe. Thus, the optimal price schedule is $\min \left[P^{m}(q), c q\right]$ and the associated quantity is $\max \left[q^{m}(\theta), q^{e}(\theta)\right]$, where $q^{e}(\theta)$ is implicitly defined as the solution to $u_{q_{A}}\left(q_{A}, 0, \theta\right)=c$. It follows that $P_{A}^{E}=\min \left[P^{m}(q), c q\right]$ possibly plus a constant term. In particular, $P_{A}^{E}$ coincides with $P^{m}(q)$ if the size of the competitive advantage $c$ is sufficiently large. ${ }^{14}$

The aforementioned constant terms remains to be characterised. These constants implicitly determine in which states of demand the buyer will sign an exclusive contract or a non-exclusive one, and the switching points between the two regimes. At any optimal switching point $\hat{\theta}$ the following conditions must hold:

$$
u\left(q_{A}^{E}(\hat{\theta}), 0, \hat{\theta}\right)-P_{A}^{E}\left(q_{A}^{E}(\hat{\theta})\right)=v\left(q_{A}^{N E}(\hat{\theta}), \hat{\theta}\right)-P_{A}^{N E}\left(q_{A}^{N E}(\hat{\theta})\right),
$$

and

$$
\frac{P_{A}^{N E}\left(q_{A}^{N E}(\hat{\theta})\right)-P_{A}^{E}\left(q_{A}^{E}(\hat{\theta})\right)}{v_{\theta}\left(q_{A}^{N E}(\hat{\theta}), \hat{\theta}\right)-u_{\theta}\left(q_{A}^{E}(\hat{\theta}), 0, \hat{\theta}\right)}=\frac{1-F(\hat{\theta})}{f(\hat{\theta})}
$$

where $q_{A}^{E}(\theta)$ and $q_{A}^{N E}(\theta)$ are the equilibrium quantities associated with $P_{A}^{E}\left(q_{A}\right)$ and $P_{A}^{N E}\left(q_{A}\right)$, respectively.

Condition (6) follows from the fact that the firm offers both exclusive and non-exclusive contracts, and the buyer can freely choose which type of contract to sign. This implies that at the switching point the buyer must be indifferent between exclusive and nonexclusive contracts. Condition (7), on the other hand, follows from the firm's optimisation. To prove it, let $\Phi$ be a parallel shift in the price schedules that apply for $\theta \geq \hat{\theta}$. Notice that a change in $\Phi$ will not affect the equilibrium quantities for $\theta>\hat{\theta}$. Therefore,

\footnotetext{
${ }^{14}$ To be precise, the condition is $c \geq c^{m}$. The reason why the critical threshold is again $c^{m}$ is as follows. Since the goods are imperfect substitutes, it is clear from the definitions that $q^{e}(\theta) \leq q^{\lim }(\theta)$, with equality only when both quantities vanish. The lowest $c$ such that $q^{m}(\theta)$ always exceeds $q^{e}(\theta)$ must therefore coincide with the lowest $c$ such that $q^{m}(\theta)$ can exceed $q^{\lim }(\theta)$.
} 
a small increase $d \Phi$ in $\Phi$ will increase profits by $[1-F(\hat{\theta})] d \Phi$. On the other hand, a change in $\Phi$ will change $\hat{\theta}$. By implicit differentiation, the corresponding change in profits is

$$
\frac{P_{A}^{N E}\left(q_{A}^{N E}(\hat{\theta})\right)-P_{A}^{E}\left(q_{A}^{E}(\hat{\theta})\right)}{v_{\theta}\left(q_{A}^{N E}(\hat{\theta}), \hat{\theta}\right)-u_{\theta}\left(q_{A}^{E}(\hat{\theta}), 0, \hat{\theta}\right)} f(\hat{\theta}) d \Phi .
$$

At an optimum, profit must be locally constant, so condition (7) follows.

For sake of simplicity, we assume that there is a unique optimal switching point $\hat{\theta}$. It should be pointed out that the solution must satisfy a no-distortion-at-the-top property, which implies that the allocation for high-demand states must be nearly efficient. Since in the baseline model exclusion is inefficient in high-demand states, exclusive dealing cannot prevail in the high-demand segment of the market. However, exclusive dealing can be optimal for low-demand states, when quantities are distorted more heavily. Therefore, exclusive dealing will prevail for $\theta<\hat{\theta}$ and common representation for $\theta>$ $\hat{\theta}$. Condition (7) then implies that the constant term of the non-exclusive price schedule is positive (i.e. a fixed fee). ${ }^{15}$

Summarising, the dominant firm offers exclusive contracts with prices $P_{A}^{E}=\min \left[P^{m}(q), c q\right]$ and non-exclusive contracts at the same prices seen in the non-linear pricing equilibrium, plus a constant term. Exclusive contracts are signed in low-demand states, and non-exclusive contracts in high-demand ones.

The equilibrium outcome is still unique, but the equilibrium price schedules are not. The reason for this is that some contracts may be destined not to be accepted and may therefore be specified arbitrarily to some extent at least. Accordingly, the following proposition specifies only the relevant parts of the equilibrium price schedules (i.e., the contracts that will be accepted in equilibrium for some realisation of demand).

PROPOSITION 2: With exclusive contracts, there is a unique equilibrium outcome. There exists a threshold $\bar{c}<c^{m}$ such that:

- when $c \leq \bar{c}$, firm A offers the price schedules:

$$
\begin{array}{ll}
P_{A}^{E}(q)=c q & \text { for } 0 \leq q \leq q^{e}(\hat{\theta}) \\
P_{A}^{N E}(q)=P_{A}^{c r}(q)+\Phi_{A} & \text { for } q \geq q^{c r}(\hat{\theta})
\end{array}
$$

where $\Phi_{A}$ is a constant term;

- when $\bar{c} \leq c \leq c^{m}$, firm A offers the price schedules:

$$
P_{A}^{E}(q)= \begin{cases}c q & \text { for } 0 \leq q \leq q_{A}^{m}(\bar{\theta}) \\ P^{m}(q)+\text { constant } & \text { for } q_{A}^{m}(\bar{\theta}) \leq q \leq q_{A}^{m}(\hat{\theta})\end{cases}
$$

where $\bar{\theta}$ is the solution to $q^{e}(\bar{\theta})=q_{A}^{m}(\bar{\theta})$, and the constant guarantees the conti-

\footnotetext{
${ }^{15}$ The constant term of the exclusive price schedule, which applies to the marginal buyer, must be nil, for those reasons given in footnote 12 .
} 
nuity of the price schedule, and

$$
P_{A}^{N E}(q)=P_{A}^{c r}(q)+\Phi_{A} \quad \text { for } q \geq q_{A}^{c r}(\hat{\theta}) ;
$$

- when $c \geq c^{m}$, firm A offers the price schedules:

$$
\begin{array}{ll}
P_{A}^{E}(q)=P^{m}(q) & \text { for } 0 \leq q \leq q_{A}^{m}(\hat{\theta}) \\
P_{A}^{N E}(q)=P_{A}^{c r}(q)+\Phi_{A} & \text { for } q \geq q_{A}^{c r}(\hat{\theta}) .
\end{array}
$$

In each case, $\hat{\theta}$ and $\Phi_{A}$ are determined by the equilibrium conditions (6) and (7).

\section{B. Discussion}

We now discuss the main qualitative properties of the equilibrium.

We start from the case in which the competitive advantage is relatively large, i.e. $c \geq$ $c^{m}$. Panel $a$ of Figure 1 depicts the equilibrium quantities under non-linear pricing. In this case, in low-demand states the buyer is effectively captive, so the dominant firm can engage in monopoly pricing. As demand increases, however, the buyer is increasingly tempted to also purchase product $B$. However, if the buyer purchased a positive amount of product $B$, his demand for product $A$ would decrease, as the products are substitutes. To prevent this, the dominant firm therefore engages in limit pricing, by raising sales of product $A$ just to the point where the marginal willingness to pay for product $B$ equals the competitive fringe's cost $c$. Finally, when demand increases further, foreclosing the competitive fringe becomes too costly. The dominant firm therefore accommodates the competitive fringe, and in equilibrium the buyer purchases both products.

[Insert Figure 1 about here]

[Caption: Equilibrium quantities when the competitive advantage is large.]

Now, consider how the equilibrium changes in the case of exclusive contracts (panel $b$ ). Notice that limit pricing is a second best strategy from the dominant firm's viewpoint: it is less profitable than monopoly pricing, and has to be adopted simply because of the competitive pressure exercised by the fringe. The role of exclusive contracts is to eliminate such pressure.

Of course, the buyer has the option of refusing exclusive deals and trading with the competitive fringe only. In this case, however, this option does not really constrain the dominant firm. This is so because the buyer obtains an information rent even under monopoly. When $c \geq c^{m}$, this is actually larger than the rent that he could obtain by trading exclusively with the competitive fringe. As a result, exclusive dealing effectively shelters the dominant firm from the competitive pressure from the fringe in utility space, at no cost. 
To put it differently, by using exclusive contracts the dominant firm can turn the competition for each marginal unit of demand into competition for the entire volume demanded by a buyer. This allows the dominant firm to better exploit its competitive advantage. By leveraging on the rents that it inevitably must leave on inframarginal units, the dominant firm can keep selling the monopoly quantity in states of greater demand, without having to resort to limit pricing. Thus, exclusive contracts allow dominant firms to more profitably exclude competitors from a segment of the market. This is perhaps the main conclusion of this paper.

Partial foreclosure. Note that when $c \geq c^{m}$ the competitive advantage is so large that in principle the dominant firm could impose exclusive dealing, and sell monopoly quantities at monopoly prices, for all states of demand. However, the most profitable strategy is to eventually accommodate the competitive fringe, allowing the buyer to purchase both products in high-demand states.

The intuitive reason for this is that exclusive dealing reduces total surplus, thus imposing an unnecessary cost on the buyer. ${ }^{16}$ However, exclusive dealing allows better screening. In particular, the buyer values the opportunity to purchase both products more in high-demand states than in low-demand ones, and therefore has more to lose from accepting exclusive contracts when demand is high. This suggests that it may be profitable to impose exclusive dealing only in low-demand states.

That this must indeed be so follows from a no-distortion-at-the-top property. Remember that with full information, an efficient outcome is always achieved (O'Brien and Shaffer, 1997; Bernheim and Whinston, 1998). When demand is high, the dominant firm must then find it profitable to maximise the surplus and extract it as best as it can, just as it would have done under complete information. Thus, exclusive dealing is not imposed in high-demand states. As a result, the competitive fringe is not driven out of the market completely.

It should be pointed out that partial foreclosure is optimal not because total foreclosure is too costly, but because the dominant firm actually benefits from the presence of the competitive fringe. The reason for this is that when $c \geq c^{m}$ the fringe does not exert any effective competitive pressure on the dominant firm, but raises the total surplus from trade by supplying a differentiated product for which there is demand. The dominant firm takes advantage of this by extracting part of the additional surplus. ${ }^{17}$

Prices and profits. In high-demand states, the buyer obtains exactly the same quantities as he would do in the non-linear pricing equilibrium. However, the payments in the two cases are different. In particular, with exclusive contracts the dominant firm adds a fixed fee to its non-exclusive tariff (marginal prices cannot change as they must support the same quantities). This fixed fee can be interpreted as a "tax" levied on product variety. This is illustrated in Figure 2.

\footnotetext{
${ }^{16}$ Formally, $u\left(q_{A}, 0, \theta\right) \leq v\left(q_{A}, \theta\right)$, with strict inequality whenever exclusion is inefficient. From this viewpoint, exclusive dealing resembles the strategy of damaging one's goods analysed by Deneckere and McAfee (1996). One difference, however, is that with exclusive contracts, most of the cost of the damage is borne by the firm's rivals, which makes the strategy more attractive.

${ }^{17}$ This is similar to Chen and Rey (2012).
} 
[Insert Figure 2 about here]

[Caption: Equilibrium prices when the competitive advantage is large.]

The figure also shows that for certain intermediate demand states the dominant firm can keep charging monopoly prices without resorting to limit pricing, as explained above. Thus, the dominant firm's prices clearly increase.

Now compare tariffs $P_{A}^{E}\left(q_{A}\right)$ and $P_{A}^{N E}\left(q_{A}\right)$ in panel $b$ of Figure 2. It appears that at the switching point between the exclusive and non-exclusive regimes, the average price goes up. On the other hand, the marginal price goes down. In other words, the curve $P_{A}^{N E}\left(q_{A}\right)$ is atter than the curve $P_{A}^{E}\left(q_{A}\right)$. Intuitively, lower non-exclusive marginal prices serve to compete more effectively for marginal units. The upward jump in average prices, on the other hand, serves to induce the buyer to accept exclusive deals. Thus, the dominant firm effectively offers exclusivity discounts. Compared to the non-linear price equilibrium tariff, however, such "discounts" result from a surcharge on non-exclusive deals, rather than from any discount on exclusive deals.

Notice also that our normalisation of costs implies that $P_{A}^{E}\left(q_{A}\right)$ and $P_{A}^{N E}\left(q_{A}\right)$ are the marginal profits earned from a buyer who buys $q_{A}$ units of the good in the two regimes. Therefore, at the switching point the marginal profit is higher under common representation. The economic reason for this is simple. Consider an increase in the constant term of the tariff that applies for $\theta>\hat{\theta}$, i.e. the non-exclusive tariff. Clearly, this move has a direct, positive effect on profits extracted in higher states, and an indirect effect due to the resulting increase in $\hat{\theta}$. The indirect effect would vanish if $P_{A}^{N E}\left(q_{A}^{N E}(\hat{\theta})\right)=P_{A}^{E}\left(q_{A}^{E}(\hat{\theta})\right)$. At the optimum, however, the indirect effect must be negative since it must exactly offset the positive, direct effect. This implies that profitability must be greater to the right than to the left of the switching point. Therefore, the dominant firm should actually welcome a switch to common representation, although (or rather, precisely because) it sets its prices so as to penalise such a switch.

Product variety. The dominant firm forecloses the competitive fringe more extensively with exclusive contracts than by using limit pricing: with reference to Figure $1, \hat{\theta}>\breve{\theta}_{B}$. This implies that the dominant firm's market share tends to increase.

In the light of the foregoing analysis, this result is clear. Since exclusive dealing is more profitable than limit pricing as a foreclosure strategy, the dominant firm uses it more widely. As a result, fewer buyers purchase both goods when exclusive contracts are permitted than when they are prohibited: consequently, there is less product variety.

Welfare effects. We can now summarise our results and note the implications for welfare. That the dominant firm benefits from exclusive contracts follows from a simple revealed preference argument. More specifically, we have seen that the dominant firm's market share rises, while at the same time it can also raise its prices.

In a competitive fringe model, the dominant firm's competitors cannot really be harmed, as they would just break even anyway. However, buyers are harmed in terms of both higher prices and less variety. To be precise, in low-demand states buyers are unaffected; in intermediate-demand states they obtain the monopoly quantity rather than either the limit pricing quantities or the common representation quantities; and in high-demand 
states, where quantities do not change, they are negatively affected by the fixed fee added to the non-linear pricing equilibrium tariff. (Intuitively, since the quantities obtained in lower-demand states are more heavily distorted, the firm can extract higher rents in higher-demand states. $)^{18,19}$

The impact of exclusive contracts on social welfare is also negative. This follows immediately from the fact that the equilibrium quantities are never greater than under non-linear pricing, and are strictly lower in certain intermediate-demand states. In such states, buyers obtain the monopoly quantity rather than either the limit pricing or the common representation quantities. This entails a greater distortion, and is thus detrimental to social welfare.

Qualitatively similar results hold when $c^{\lim } \leq c<c^{m}$. There are only two relatively minor changes. Firstly, under non-linear pricing the monopoly region (i.e. for low-demand states) disappears, and the marginal buyer is served under limit pricing. Secondly, the dominant firm cannot implement the monopoly solution in all cases in which the buyer signs an exclusive contract, as the monopoly tariff now lies above the fringe's price (i.e. the $c q$ line) when $q$ is small. In other words, the competitive pressure from the competitive fringe forces the dominant firm to set the exclusive prices at cost, and hence the exclusive quantity at $q^{e}(\theta)$, for some low-demand states. However, in such low-demand states the buyer would have purchased the limit pricing quantity $q^{\lim }(\theta)$ under non-linear pricing. Since this is higher than $q^{e}(\theta)$, as the goods are imperfect substitutes, the buyer is still harmed, and social welfare is negatively affected. We can therefore conclude that exclusive contracts are unambiguously anticompetitive in this case as well.

The case where the competitive advantage is small (i.e. $c<c^{\lim }$ ) is somewhat different, since firm A's dominance is due not so much to its competitive advantage (which is indeed low) as to the lack of market power of product $B$ 's suppliers. As a result, under non-linear pricing in low-demand states the buyer purchases product $B$ only (see panel $a$ of Figure 3).

This cannot occur when product $B$ is offered by a duopolist that also possesses market power. As a result, in the duopoly model the case of limited competitive advantage results in economic effects that are quite different from those found in the competitive fringe model, as we shall see below.

\footnotetext{
${ }^{18}$ It may be tempting to view buyers who sign exclusive contracts as imposing a negative externality on those who do not, in a similar way to what happens in models of "naked exclusion." However, this analogy is misleading. A buyer's payoff depends only on his trades with the firms, and not on other buyers' trades. It should also be pointed out that exclusive contracts would be profitable and anticompetitive even if the contracts intended for high-demand states remained the same as in the non-linear pricing equilibrium.

${ }^{19}$ When buyers are downstream firms, the extent to which their gains or losses are shifted onto final consumers may depend on how exactly prices change. Generally speaking, higher upstream prices tend to result in higher downstream prices, so final consumers will also suffer from exclusive contracts when downstream firms do. However, if the only change is an increase in a fixed fee, final consumers may be unaffected.
} 
[Insert Figure 3 about here]

[Caption: Equilibrium quantities when the competitive advantage is small.]

Besides being socially inefficient, the fact that in low-demand states the buyer purchases product $B$ only, is disappointing from the point of view of the dominant firm. If only the dominant firm could replace the competitive fringe in the low-demand segment of the market, it would save the corresponding production cost and increase its profits by the saved amount. However, to achieve that result the dominant firm would have to undercut the competitive fringe. With non-linear pricing, this would improve the buyer's contractual options in high-demand states: the buyer could now purchase, at a unit price of $c$, a certain amount of product $A$ in addition to any amount of product $B$. This possibility would reduce the rent that the firm can extract in high-demand states, offsetting any gains in low-demand ones.

With exclusive contracts, however, the dominant firm can undercut the competitive fringe in low-demand states under an exclusivity clause. This leaves the buyer's contractual options in high-demand states unchanged. (Note that the buyer can already purchase any amount of one product, namely $B$, at a unit price of $c$.) It follows that the dominant firm can now replace the competitive fringe in the low-demand segment of the market, without losing any profit in the high-demand segment. Figure 3 (panel $b$ ) illustrates this.

Again, buyers are clearly harmed by exclusive contracts. The fact that the equilibrium quantities, which are already inefficiently low under non-linear pricing, are further reduced has a negative impact on social welfare. Now, however, exclusive contracts have a positive productive efficiency effect. That is, replacing the competitive fringe in lowdemand states reduces total production costs. This may make the total welfare effect of exclusive contracts uncertain.

We conclude our discussion of the baseline model by noting that in the limiting case $c=0$, exclusive contracts become irrelevant. This confirms that the anticompetitive mechanism analysed in this paper crucially hinges on the dominant firm's competitive advantage.

\section{Extensions}

In this section, we discuss the case in which the dominant firm faces competition from one small rival firm which, however, exercises a certain market power. We also consider the case in which exclusion is efficient when demand is high rather than when demand is low. For the sake of simplicity, we focus on uniform-quadratic specifications of the model, where explicit solutions can be derived. Formal analyses and proofs for this section may be found in the online Appendix (Sections 3 and 4).

\section{A. Duopoly}

In principle, the case in which there is only one supplier of product $B$ (which we shall call firm $B$ ) might open up new possibilities. Unlike the competitive fringe, firm $B$ can actively respond to the dominant firm's attempt at foreclosing it. In particular, it may 
offer exclusive contracts in turn, lower its non-exclusive prices, or both. Therefore, the party offering exclusive contracts, and whose contracts are accepted in equilibrium, is now endogenous.

The duopoly model is also technically more complex than the competitive fringe model. The main reason for this is that the solution to a firm's pricing problem does not yield directly the equilibrium, but only its best response to its rival's strategy. Finding the equilibrium requires finding a fixed point of the best response correspondence.

As it turns out, however, when the dominant firm's competitive advantage is large, the results do not change substantially from the competitive fringe model. Qualitatively, equilibrium quantities and prices are the same as in Figures 1 and 2. However, there are a few notable differences that we shall now discuss.

First of all, firm $B$ too may now offer exclusive contracts. If it does, ${ }^{20}$ it prices exclusive deals at cost. However, the dominant firm either undercuts firm $B$ in Bertrand-like fashion, or else it engages in monopoly pricing - whichever leads to lower prices. As a result, only the exclusive contracts offered by the dominant firm are accepted in equilibrium. In practice, this implies that only $A$ 's exclusive contracts can be observed.

Secondly, firm $B$ now exercises whatever market power it has thanks to product differentiation, by charging supra-competitive non-exclusive prices. As a result, the common representation quantities are different than in the baseline model. To be precise, under duopoly $q_{B}^{c r}(\theta)$ is smaller, and $q_{A}^{c r}(\theta)$ greater. $^{21}$

Thirdly, firm $B$ now actively resists being foreclosed. Besides pricing its exclusive contracts as aggressively as it can, it also cuts its non-exclusive prices. Compared to the non-linear pricing tariff, firm $B$ offers a lump-sum subsidy to a buyer who switches to common representation. Firm $A$, in contrast, charges him a fixed fee, precisely as it does in the competitive fringe model. Clearly, firms are competing for market shares. Firm $A$ tries to induce the buyer into accepting exclusive dealing arrangements, and firm $B$ to opt for common representation. However, the fact that firms use lump-sum transfers for competing at the extensive margin implies that the common representation quantities are exactly the same as in the non-linear pricing equilibrium. This is similar to the baseline model.

Finally, firm $B$ now obtains a positive profit (gross of fixed costs). Hence, it can be definitely harmed by exclusive contracts. Indeed, firm $B$ is harmed both because its sales shrink, and because it must reduce its prices in order to resist being excluded from an even larger segment of the market.

However, things are quite different when the dominant firm's competitive advantage is small. In this case, there is a countervailing procompetitive effect that may outweigh the anticompetitive effect that we have analysed so far. This procompetitive effect has been analysed in Calzolari and Denicolò (2013), which focuses on the symmetric case $c=0$.

To clarify matters, one should remember that firms may compete for marginal units (if exclusive contracts are banned) or for the entire volume demanded by a buyer (if ex-

\footnotetext{
${ }^{20}$ If $c \geq c^{m}$, it is in fact irrelevant whether firm $B$ offers exclusive contracts or not.

${ }^{21}$ For the same reason, $q^{\lim }(\theta)$ is lower than in the competitive fringe model, and is now lower than $q^{e}(\theta)$ for small values of $\theta$.
} 
clusive contracts are permitted). Which form of competition is tougher depends on the relative strength of two opposing effects. On the one hand, in utility space the dominant firm can leverage the rents that it must inevitably leave to buyers. This allows the dominant firm to make more effective use of its competitive advantage, gaining more protection from competition. On the other hand, in utility space competition is not softened by product differentiation. This implies that the dominant firm's rivals tend to price more aggressively.

This procompetitive effect is mute in the competitive fringe model, where the fringe always prices at cost. However, it comes into play in the duopoly model. Since the anticompetitive effect vanishes when $c=0$, as we have seen above, in a duopoly the procompetitive effect must prevail when the competitive advantage is relatively small. On the other hand, the anticompetitive effect must prevail when the competitive advantage is large. To be precise, we have:

PROPOSITION 3: In the duopoly uniform-quadratic model (2), there exists a critical value of the competitive advantage $c^{*}$ such that exclusive contracts reduce social welfare when $c>c^{*}$ and increase social welfare when $c<c^{*}$.

A similar result holds if one focuses on buyers' surplus only. This shows that the results found in Calzolari and Denicolò (2013) are robust to a small degree of asymmetry, but are reversed when the dominant firm's competitive advantage is large enough.

\section{B. Biased competitive advantage}

Our baseline model assumes that the dominant firm's competitive advantage is independent of the state of demand. However, the size of the competitive advantage might depend on $\theta$. Generally speaking, the competitive advantage could be greater for low values of $\theta$ (i.e., low-demand biased), or for high values of $\theta$ (i.e., high-demand biased).

When the competitive advantage is constant, as in the baseline model, exclusion may be efficient when demand is low, but is inefficient when it is high. Intuitively, a constant competitive advantage counts relatively more when demand is low. This implies that exclusive contracts should be signed in low-demand states, but not in high-demand ones. The same conclusion holds, a fortiori, when the competitive advantage is low-demand biased.

Things may be different, however, when the competitive advantage is high-demand biased. For example, this case may arise when large buyers have a stronger preference for the dominant firm's product - a possibility that is not unlikely when the dominant firm supplies a product of higher quality. In this case, exclusion may be efficient when demand is high. As a result, exclusive contracts may be signed by large buyers. This may help reconcile the model with a variation observed in the empirical evidence: exclusive contracts are sometimes signed by small buyers, and in other cases by large buyers. In recent antitrust cases, for instance, exclusive contracts prevail for small buyers in Dentsply and Gilbarco, but for large buyers in Intel. ${ }^{22}$

${ }^{22}$ In Dentsply, the five major buyers (i.e. distributors of artificial teeth) also distributed the dominant firm's competi- 
To model the case of biased competitive advantage, consider for instance the following payoff function:

$$
u\left(q_{A}, q_{B}, \theta\right)=(1+\theta) q_{A}+(1+b \theta) q_{B}-\frac{1-\gamma}{2}\left(q_{A}^{2}+q_{B}^{2}\right)-\gamma q_{A} q_{B},
$$

with $\theta$ uniformly distributed over the interval $[0,1]$ (and $c$ set to 0 ). With this specification, the case of high-demand biased competitive advantage is captured by setting $b<1$. If $b$ is small enough, exclusion may now be efficient in high-demand states, but inefficient in low-demand ones.

In what follows, we focus only on the case in which the competitive advantage is sufficiently large that exclusion is indeed efficient in high-demand states. To be precise, assume that $b \in[0, \bar{b}]$, where $\bar{b}=\frac{3 \gamma-1}{1-\gamma} .^{23}$

PROPOSITION 4: In the biased competitive advantage model (8), when the competitive advantage is sufficiently large:

- there is a unique non-linear pricing equilibrium in which the competitive fringe prices at cost (i.e. $P_{B}=0$ ) and firm A offers the price schedule

$$
P_{A}(q)= \begin{cases}P_{A}^{c r}(q) & \text { for } 0 \leq q \leq q^{\lim }\left(\breve{\theta}_{B}\right) \\ P^{\lim }(q)+\text { constant } & \text { for } q^{\lim }\left(\breve{\theta}_{B}\right) \leq q \leq q^{m}\left(\theta^{\lim }\right) \\ P^{m}(q)+\text { constant } & \text { for } q \geq q^{m}\left(\theta^{\lim }\right),\end{cases}
$$

where the constants guarantee the continuity of the price schedule;

- with exclusive contracts, there is a unique equilibrium outcome. The competitive fringe always prices at cost, whereas firm A offers the price schedules

$$
\begin{array}{ll}
P_{A}^{N E}(q)=P_{A}^{c r}(q) & \text { for } 0 \leq q \leq q_{A}^{c r}(\hat{\theta}) \\
P_{A}^{E}(q)=P^{m}(q)+\Phi_{A} & \text { for } q \geq q_{A}^{m}(\hat{\theta})
\end{array}
$$

where $\hat{\theta}$ and $\Phi_{A}$ are determined by the equilibrium conditions (6) and (7).

As in the baseline model, exclusive contracts serve as a better substitute for limit pricing. However, the model now predicts exclusive outcomes in high-demand states, and common representation outcomes in low-demand ones.

Figure 4 (panel $a$ ) shows the non-linear pricing equilibrium quantities. When demand is low, buyers purchase product $B$ only, as the competitive fringe prices more aggressively than the dominant firm. As $\theta$ increases, the demand for product $A$ increases more strongly

tors' products. Similarly, in Gilbarco major oil companies purchased retail petroleum dispensers from more than one manufacturer. In Intel, on the other hand, the allegedly anticompetitive contracts were signed by some of the largest buyers, such as Dell, HP and Lenovo. Cases Dentsply and Intel are discussed at greater length in section 3. Frasco (1991) provides an overview of older exclusive dealing cases, which shows that both patterns are observed in practice.

${ }^{23}$ The interval is non-empty if the goods are sufficiently strong substitutes, i.e. $\gamma>1 / 3$. 
than that of product $B$. As a result, we now have common representation first, followed by limit pricing and, eventually, by monopoly.

[Insert Figure 4 about here]

[Caption: Equilibrium quantities with biased competitive advantage.]

The effects of exclusive contracts are illustrated in panel $b$. The competitive fringe is foreclosed in high-demand states. To be precise, when demand is very high, de facto exclusivity is already obtained under simple non-linear pricing. However, for intermediate values of demand, exclusive dealing must be imposed contractually. Finally, in low-demand states, the buyer will either be served under common representation, or else purchases product $B$ only.

In addition to reversing the result regarding who signs exclusive contracts and who does not, this alternative specification also affects two other results of the baseline model. As in the baseline model, in the equilibrium depicted in Figure 4, marginal profits are increasing with demand and they jump up at the switching point. However, as demand increases the switch is now from common representation to exclusive dealing. Therefore, the dominant firm now earns more, at the switching point, under exclusive dealing than under common representation. Hence, it will not welcome a switch to common representation.

Secondly, it can be shown that in equilibrium $\Phi_{A}$ is negative. That is, the dominant firm now offers lump-sum subsidies for exclusivity, rather than imposing a lump-sum tax on product variety. It can also be shown that the amount of the lump-sum discounts increases as the size of the competitive advantage decreases.

\section{Applications}

In this section we illustrate how the analysis developed so far can be applied to a realworld antitrust case. In doing so, we contrast our theory with alternative explanations of exclusive contracts proposed in the literature.

For the purposes of our illustration we use the Intel case. Intel produces microprocessors, i.e. integrated circuits that are used by Original Equipment Manufacturers (OEMs) to produce computers. From 2001 to 2007, Intel allegedly entered into exclusive dealing arrangements and market-share contracts with various OEMs, including Dell, HP, NEC and Lenovo. ${ }^{24}$ The case has been the subject of extensive litigation both in Europe and in the US. ${ }^{25}$

\footnotetext{
${ }^{24}$ It should be pointed out that Intel used a variety of contractual formats. For example, Dell agreed to an exclusive dealing arrangement, whereas HP and NEC agreed to market-share contracts with market-share targets set at 95\% for HP and $80 \%$ for NEC. Such market-share contracts are analysed in the online Appendix (section 5), which shows that their effects are qualitatively similar to those of exclusive contracts.

${ }^{25}$ In Europe the case has gone all the way to the European Court, whose decision is still pending, and has resulted in the largest fine ever seen in the history of European competition policy so far, over a billion Euro. In the US, a private antitrust action by AMD and two court challenges by the FTC and the New York State General Attorney were all eventually settled. Intel agreed to stop the practices and pay AMD damages of $\$ 1.25$ billion. Related lawsuits were also brought in certain individual European countries, in Japan and in Korea.
} 
We choose this example for three main reasons. Firstly, the case is important in its own right: the microprocessor industry is essential to the modern economy, Intel is a large company, and the litigation has sparked a heated debate. ${ }^{26}$ Secondly, the aforementioned lawsuits have together resulted in a detailed account of Intel's relations with OEMs. Although we do not have access to confidential case material, the public evidence is more detailed than for many other cases. ${ }^{27}$ Thirdly, the market structure seems broadly consistent with our assumptions. In particular, Intel was a dominant firm, but not a monopolistic one $;^{28}$ dominance was largely attributable to Intel's competitive advantage over its competitors, in terms of both lower costs and higher perceived quality; ${ }^{29}$ the products were imperfect substitutes and buyers had a preference for variety; ${ }^{30}$ and finally there is indirect evidence of the importance of asymmetric information. ${ }^{31}$

The anticompetitive mechanism analysed in this paper implies that exclusive contracts increase the dominant firm's market share and allow it to raise its prices. Unfortunately, in the microprocessor industry technological change is so fast that identifying the effects of Intel's contractual practices on prices and market shares is a daunting task. ${ }^{32}$ On the face of it, the evolution of market shares seems consistent with our theory. ${ }^{33}$ However, there are so many confounding factors that this fact in itself is inconclusive. Credible causal statements require an empirical structural model that incorporates Intel's pricing strategies, which is beyond the scope of this paper.

The validity of the model's qualitative predictions can be assessed more easily. Firstly, the model predicts that the smaller firm will not offer exclusive contracts - or, if it does, that only the exclusive contracts offered by the dominant firm will be accepted in equilibrium. Indeed, there is no evidence in the public records that any OEM had signed exclusive contracts with AMD. This observation may raise doubts about the validity, in

\footnotetext{
${ }^{26}$ It has also inspired a considerable amount of academic research: see for instance DeGraba (2013), DeGraba and Simpson (2013), Johnson (2012), Wright (2011), and Chen and Sappington (2011).

${ }^{27}$ In what follows, we shall mainly refer to the following documents: the European Commission's Decision C(2009) 3726 of 13 May 2009 (the EU decision); the General Court's Judgement T-286/09 of 12 June 2014 (the EU appeal); and the New York Attorney General's Complaint of 3 November 2009 (the NYAG complaint).

${ }^{28}$ Intel consistently boasted a market share of more than $80 \%$ over the period in question but faced ongoing competition from AMD (with a market share around 15\%) and a few other smaller competitors. See, for instance, DeGraba and Simpson (2013). The fact that the incumbent faces actual rather than potential competition is common to many antitrust cases. Models where an incumbent competes with a potential entrant are not directly applicable to such cases.

${ }^{29}$ Goettler and Gordon (2011) estimate that final consumers were willing to pay almost \$200 more for the Intel brand than for the AMD brand, on top of any price difference re ecting the objectively measurable performances of the microprocessors in question. They also report that Intel benefited from lower unit costs during the period in question.

${ }^{30}$ There is extensive evidence that OEMs valued the possibility of offering broad product lines that included AMD based products very highly: see, for instance, EU decision paras 183-6; NYGA complaint, paras 92, 152-6.

${ }^{31}$ Intel did not make any take-it-or-leave-it offer, but proposed contracts in which prices were conditional on various factors such as volumes, participation in joint marketing campaigns, and the meeting of exclusivity (or market-share) requirements. Such conditional pricing strategies may naturally be viewed as a means of inducing buyers to self-select in situations of asymmetric information.

${ }^{32}$ The identification of possible price effects is especially difficult. Listed prices are observable, but Intel negotiated substantial discounts with individual OEMs. Annual average prices may be recovered from OEMs' balance sheets, but the exact pricing schemes were confidential. Even the investigations conducted by European and American antitrust authorities revealed such schemes only partially.

${ }^{33}$ After reaching a low in 2001, Intel's market share recovered in the subsequent years, falling again in 2006 when Dell broke the exclusive dealing agreement. Meanwhile, the relative quality of AMD's microprocessors was improving (Goettler and Gordon, 2011, p. 1147), suggesting that the temporary increase in Intel's market share may be attributable to its more aggressive contractual practices.
} 
this particular case, of the various pro-efficiency explanations of exclusive contracts that have been proposed in the literature. Such explanations may be plausible when exclusive contracts are employed by all active firms, but may be viewed with a certain scepticism when exclusive contracts are used by the dominant firm only. ${ }^{34}$

Secondly, Intel's contracts with OEMs were informal and implicit. They could be terminated at will, or at very short notice, without any contractual penalty being incurred..$^{35}$ This does not affect the applicability of our theory, in which contracts play no commitment role. However, it may be a problem for theories that rely on players' commitment to signed contracts. ${ }^{36}$ It is even more problematic for the applicability of theories in which penalties for breach of exclusive dealing are crucial if such arrangements are to be profitable and anticompetitive. ${ }^{37}$

Thirdly, the amount of the market foreclosed by Intel was not particularly large. In its appeal lodged with the European General Court, Intel pointed out, and the court agreed, that its contracts could only foreclose less than $14 \%$ of the market. ${ }^{38}$ Intel argued that this would leave plenty of room for a competitor to achieve economies of scale and prosper. However, this does not pose any problems for our theory, which does not view exclusive contracts as a means to raise rivals' costs.

Fourthly, it seems clear that AMD was never under any real threat of shutdown. ${ }^{39}$ This makes life more difficult for theories that presume some form of recoupment, ${ }^{40}$ because it rules out intertemporal recoupment. Since recoupment is not necessarily intertemporal (for example, it might take place in a related market), the observation is not dispositive. However, it should be pointed out that the issue does not arise in our analysis, where exclusive contracts are directly profitable and do not entail any sacrifice of profits.

That the dominant firm's competitors do not offer exclusive contracts, that the contracts are short-term, that the amount of the market foreclosed is relatively small, and that rivals are not actually driven out of the market - all of this is also true in various other antitrust cases. ${ }^{41}$ However, the Intel case provides a rare opportunity to assess

\footnotetext{
${ }^{34}$ See Whinston (2008) for an excellent discussion of the possible pro-efficiency rationales for exclusive arrangements. In fact, Intel did not invoke any such rationale to justify its practices.

${ }^{35}$ EU decision para 190; NYGA complaint para 85.

${ }^{36}$ Commitment is important in theories based on the limited scope for negotiations, such as those of Rasmusen, Ramseyer and Wiley (1990) or Chen and Shaffer (2014). Should negotiations that initially could not take place become subsequently feasible, the parties would have an incentive to renegotiate - a point that has been forcefully made by Spier and Whinston (1995).

${ }^{37}$ Aghion and Bolton (1987), for example, assume the existence of penalties for breach of exclusivity. Figueroa, Ide and Montero (2014) argue that such penalties are crucial for the contracts to be anticompetitive. See also Choné and Linnemer (2015) and Ide, Montero and Figueroa (2015).

${ }^{38}$ EU appeal, paras 183-94.

${ }^{39}$ AMD's market share never fell below 12\% over the period in question (DeGraba and Simpson, 2013). Stock price data also confirm that AMD always remained a viable competitor (Wright, 2011).

${ }^{40}$ For example, the European Commission argued that if Intel's discounts had been attributed to "contestable" sales only, they would have entailed below-cost pricing: see EU decision paras 1002-1508.

${ }^{41}$ Recent examples include, for instance, Omega v. Gilbarco, 3M v. Appleton, and United States v. Dentsply. This last case is one of the few recent instances in the US of enforcement agency challenges to exclusive dealing arrangements. Dentsply was the leading manufacturer of artificial teeth. By the end of the ' $90 \mathrm{~s}$, it had a market share of $65-70 \%$ in terms of units, and of $75-80 \%$ in terms of value. It faced competition from a fringe comprising a dozen competitors, the largest of which controlled less than 5\% of the market. In 1993, Dentsply entered into exclusive or near-exclusive agreements with a certain number of dental dealers. These are intermediaries that distribute the products to end users, i.e., dental
} 
certain of our theory's more specific predictions, regarding the switch from exclusive to non-exclusive contracts. Such switches may occur naturally following changes in the realisation of demand and/or in the size of the competitive advantage, and are indeed observed in the Intel case. In particular, we possess detailed information on the long, complicated process that eventually led Dell to switch from exclusive dealing to common representation in 2006.

Both the baseline model and the model with biased competitive advantage predict that (i) the dominant firm charges a greater average price to buyers who switch to common representation, whereas the marginal price goes down as the dominant firm must now compete for marginal units. Furthermore, both models predict that (ii) the dominant firm's competitor offers lump-sum discounts to buyers who switch to common representation.

As for prediction (i), the European Commission provides evidence that the average price went up after Dell broke the exclusive dealing agreement. However, Intel disputed this conclusion, arguing that under common representation it would have had a stronger incentive to lower its marginal prices. We do not have access to Intel's submission, nor to the evidence supporting its claims. However, our theory predicts that under common representation Intel would indeed charge a higher average price, but also a lower marginal price. This might reconcile the seemingly opposing claims of the European Commission and Intel.

There is also evidence consistent with result (ii). In particular, when HP first considered launching AMD based products in a certain segment of the market, AMD offered to deliver a significant amount of CPUs to HP for free. ${ }^{42}$ This offer is equivalent to a lump-sum subsidy.

Other predictions of our theory depend on whether the competitive advantage is biased or unbiased. When the competitive advantage is unbiased (or low-demand biased), exclusive contracts are signed in low-demand states. Furthermore, the dominant firm charges a fixed fee to buyers who switch to common representation, and at the switching point the marginal profit is greater under common representation than under exclusive dealing. When the competitive advantage is high-demand biased, on the other hand, exclusive contracts are signed in high-demand states, the dominant firm offers a fixed subsidy to buyers who sign exclusive contracts, and the marginal profit is greater under exclusive dealing.

The available evidence suggests that the model with biased competitive advantage better suits the Intel case. First of all, as we have already noted, the exclusive or nearexclusive contracts were signed by some of the largest buyers, such as Dell, HP and

laboratories. The DoJ recognised that one reason why rival manufacturers failed to prosper was their failure to adapt their products to the preferences of American consumers. Nevertheless, it challenged the exclusive agreements under Section 2 of the Sherman Act. Both the district court and the appeal court agreed that: (i) Dentsply was the only manufacturer using exclusive agreements, and its proffered procompetitive justifications were pretextual; (ii) Dentsply's dealers were at liberty to terminate their contractual relations with Dentsply at any time and without penalty; (iii) rivals were not at risk of being driven out of the market. However, the courts disagreed on the size of the foreclosed portion of the market. The district court ruled for the defendant on the grounds that the amount foreclosed was small. The appeal court disagreed on this point, and overruled the district court's decision.

${ }^{42}$ NYGA complaint para 160. 
Lenovo. Secondly, it seems that Intel did not charge fixed fees under common representation. Rather, it offered lump-sum subsidies to buyers opting for exclusive dealing. ${ }^{43}$ Thirdly, Intel did not welcome Dell's switch to common representation. On the contrary, it was seriously concerned with the possibility of such a switch. ${ }^{44}$

The biased competitive advantage model, which predicts that the amount of the lumpsum discounts will increase as the size of the competitive advantage decreases, seems also generally consistent with the history of Intel's contractual relationships with Dell. ${ }^{45}$ Before 2001, Intel's competitive advantage was large, and Dell procured all its microprocessors from Intel without any contractual restriction applying. Around the turn of the millennium, however, Intel's competitive advantage began to be whittled away. ${ }^{46}$ This process may help explain why exclusivity had to be imposed contractually in 2001 (when for the first time Intel negotiated with Dell discounts conditional upon exclusivity, the so-called 'mother-of-all-programs'), ${ }^{47}$ why Intel's lump-sum discounts to Dell were repeatedly increased from 2001 to 2006, and why Dell eventually switched to common representation in 2006.

The foregoing discussion shows that our theory is broadly consistent with many important facets of the Intel case. Of course, no abstract model can account for all features of a concrete antitrust case. For example, the microprocessor industry is highly innovative; buyers actively compete against one another; and demand may be affected by dynamic effects. Our framework abstracts from these important aspects, which lie at the centre of other models instead.

In particular, various papers have proposed a "downstream competition" theory, in which competition among downstream firms erodes any benefits they could obtain from reduced marginal prices for their inputs. As a result, downstream firms may be willing to coordinate on an equilibrium in which they obtain lump-sum subsidies from the upstream incumbent in exchange for keeping a potential entrant out: see, for instance, Asker and Bar-Isaac (2014), DeGraba (2013) and DeGraba and Simpson (2014).

Other models focus on different effects. For example, in order to capture dynamic demand effects, Johnson (2012) has developed a model in which the precise quality of product $B$ is unknown to final consumers. Since the product's quality is revealed as soon as downstream firms patronise product $B$, the dominant firm has an incentive to sign them up in order to preserve uncertainty. Chen and Sappington (2011), on the other hand, focus on innovation. They show that fully or partially exclusive contracts may deter a potential entrant's R\&D and hence impede its entry. All these models provide useful insights that may complement our analysis.

\footnotetext{
${ }^{43}$ The lump-sum nature of Intel's discounts is specifically emphasised by DeGraba and Simpson (2013). Their conclusion that Intel's discounts were at least partially of a lump-sum nature seems solid, even though Intel's pricing schemes were deliberately opaque.

${ }^{44}$ The evidence on this point is overwhelming: see for instance $E U$ decision para 240, NYGA complaint para 116.

${ }^{45}$ For a relatively brief account of such history see NYGA complaint paras 74-148.

${ }^{46}$ See Goettler and Gordon (2011, p. 1147).

${ }^{47}$ One should remember that for a range of values of $\theta$, which is larger the greater is the competitive advantage, exclusivity need not be imposed contractually.
} 


\section{Conclusion}

Summary. In this paper, we have developed a new theory of exclusive dealing. The theory supports the claim that a dominant firm may profitably use exclusive contracts to increase its market share and prices, harming buyers (in terms of higher prices and reduced variety) and rivals alike. The theory rests on two assumptions. The first assumption is that firms cannot fully extract the buyers' surplus because they are imperfectly informed about demand. The second is that the dominant firm has a sizeable competitive advantage over its rivals, in terms of lower costs, higher quality, or a combination of the two.

Not only are these assumptions often realistic, but the model's predictions are also consistent with the characteristic facts of many antitrust cases. In addition to a dominant firm that controls a substantial share of the market and has entered into some kind of exclusive arrangement with its customers, these often involve one or more smaller competitors, that have been active in the industry for some time and in principle could themselves use exclusive contracts, but apparently have chosen not to. Our theory can explain these characteristic facts and, more specifically, it can also help explain several important aspects of the Intel case, some of which may prove difficult to account for using other theories.

Our analysis, however, is not necessarily an alternative to existing anticompetitive explanations of exclusive contracts, but may well complement them. It is now widely accepted that incumbents may have a variety of reasons for foreclosing rivals: for instance, they may want to deprive rivals of economies of scale, reduce their incentives to innovate, or exploit positive dynamic externalities in demand. These motives may even justify foreclosure strategies entailing a short-term loss of profits. Our contention here is that exclusive contracts can be directly profitable. If this is so, then the aforementioned reasons may simply induce the dominant firm to behave more aggressively.

Implications for policy. The analysis developed in this paper does not call for a radical change in the current antitrust treatment of exclusive dealing arrangements in the US, which is based on the rule of reason. ${ }^{48}$ However, it may suggest that different factors should be considered for the purposes of antitrust evaluation. For example, in our model the length of the contracts is irrelevant, since contracts are not used for commitment purposes. Also, significant anticompetitive effects may be produced even if the amount of the foreclosed portion of the market is relatively limited, as the anticompetitive mechanism does not rest on raising rivals' costs.

In contrast, our analysis suggests an approach where the crucial factor is the size of the dominant firm's competitive advantage. This determines whether the dominant firm's rivals can compete for exclusives effectively (in which case procompetitive effects are possible) or not (in which case anticompetitive effects are more likely). Interestingly, this approach seems to have been foreshadowed in some recent decisions by US courts. ${ }^{49}$

\footnotetext{
${ }^{48}$ In Europe, on the other hand, exclusivity and market-share discounts have been virtually illegal per se since HoffmanLa Roche, the only possible defence being "objective justification".

${ }^{49}$ For example, the appeal court in the United States $v$. Dentsply case, in ruling against the defendant, noted the
} 
Further extensions. The oft-mentioned analogy between exclusive dealing and tying suggests that a variant of our theory may apply to tying. Indeed, this paper offers two main insights. First of all, a dominant firm that benefits from a competitive advantage over its rivals but must leave information rents to buyers, can impose contractual restrictions without having to compensate the buyers. Secondly, such restrictions can help better screen the buyers. In this paper, we have focused on contractual restrictions on what buyers can purchase from rivals. However, restrictions may be placed on what buyers must purchase from the dominant firm.

Many other possible extensions of the model may be worth considering, but for brevity we mention just three. Firstly, it seems important to extend the analysis to the case of competing buyers. In many cases, including that of Intel, the assumption that buyers are local monopolies, or final consumers, is unrealistic. In such cases, it is important to understand how competition among buyers might affect the behaviour of upstream firms. Secondly, in our model the equilibrium price schedules may be fairly complex. Firms sometimes use simpler pricing schemes, and it would be interesting to study how this affects the structure of optimal exclusive dealing arrangements. Thirdly, our analysis has been confined, for reasons of tractability, to the case of one-dimensional heterogeneity. In reality, buyers are likely to differ in many respects, and this might generate a richer set of predictions.

\section{REFERENCES}

Aghion, Philippe, and Patrick Bolton. 1987. "Contracts as a Barrier to Entry." American Economic Review 77 (3): 388-401.

Armstrong, Mark, and John Vickers. 2001. "Competitive Price Discrimination." Rand Journal of Economics 32 (4): 579-605.

Asker, John, and Heski Bar-Isaac. 2014. "Raising Retailers' Profits: On Vertical Practices and the Exclusion of Rivals." American Economic Review, 104 (2): 672-86.

Bernheim, B. Douglas, and Michael D. Whinston. 1998. "Exclusive Dealing." Journal of Political Economy 106 (1): 64-103.

Bliss, Christopher. 1988. "A theory of retail pricing." Journal of Industrial Economics 36 (4), 375-391.

Calzolari, Giacomo, and Vincenzo Denicolò. 2013. "Competition with Exclusive Contracts and Market-Share Discounts." American Economic Review, 103 (6): 2384-2411.

Calzolari, Giacomo, and Vincenzo Denicolò. 2015. "Hybrid monopolistic screening." mimeo University of Bologna.

Chen, Yongmin, and David E. M. Sappington. 2011. "Exclusive Contracts, Innovation, and Welfare." American Economic Journal: Microeconomics, 3 (2): 194-220.

Zhijun Chen and Greg Shaffer. 2014. "Naked exclusion with minimum share requirements." Rand Journal of Economics, 45 (1), 64-91.

limited ability of Dentsply's competitors to offer exclusive contracts themselves. Conversely, in RJR v. Philip Morris the district court upheld PM's program of loyalty discounts arguing, among other things, that RJR had successfully engaged in similar programs. 
Chen, Zhijun, and Patrick Rey. 2012. "Loss leading as an exploitative practice.” American Economic Review, 102 (7), 3462-82.

Choné, Philippe, and Laurent Linnemer. 2015. "Nonlinear prices and exclusion: I. buyer opportunism." Rand Journal of Economics, 46 (2): 217-40.

DeGraba, Patrick. 2013. "Naked exclusion by a dominant input supplier: Exclusive contracting and loyalty discounts." International Journal of Industrial Organization, 31 (5): 516-526.

DeGraba, Patrick and John Simpson. 2014. "Loyalty discounts and theories of harm in the Intel investigations." Journal of Antitrust Enforcement, 2 (1): 170-202..

Deneckere Raymond J. and R. Preston McAfee. 1996. "Damaged goods." Journal of Economics and Management Strategy, 5 (2): 149-174.

Figueroa, Nicolás, Enrique Ide and Juan-Pablo Montero. 2014. "Discounts as a barrier to entry." mimeo, Stanford University.

Frasco, Gregg. 1991. Exclusive dealing. A comprehensive case study, Lanham (Maryland): University Press of America.

Fumagalli, Chiara, and Massimo Motta. 2006. "Exclusive Dealing and Entry, when Buyers Compete." American Economic Review 96 (3): 785-795.

Goettler, Ronald L. and Brett R. Gordon. 2011. "Does AMD spur Intel to innovate more?" Journal of Political Economy 119 (6): 1141-1200.

Ide, Enrique, Juan-Pablo Montero and Nicolás Figueroa. 2015. "Exclusionary contracts under asymmetric information." mimeo, Stanford University.

Johnson, Justin P. 2012. "Adverse selection and partial exclusive dealing." mimeo, Cornell University.

Martimort, David. 1996. "Exclusive dealing, common agency, and multiprincipals incentive theory." Rand Journal of Economics 27 (1): 1-31.

Mathewson G. Frank and Ralph. A. Winter. 1987. "The competitive effect of vertical agreements: Comment." American Economic Review 77 (5): 1057-1062.

O’Brien Daniel P. and Greg Shaffer. 1997. "Nonlinear supply contracts, exclusive dealing, and equilibrium market foreclosure." Journal of Economics and Management Strategy 6 (4): 755-785.

Rasmusen, Eric B., J. Mark Ramseyer and John Wiley. 1991. "Naked Exclusion.” American Economic Review 81 (5): 1137-1145.

Segal, Ilya R., and Michael D. Whinston. 2000. "Naked Exclusion: Comment." American Economic Review, 90 (1): 296-309.

Shubik, Martin and Richard Levitan. 1980. Market structure and behavior. Cambridge, MA: Harvard University Press.

Simpson, John, and Abraham L. Wickelgren. 2007. "Naked Exclusion, Efficient Breach, and Downstream Competition." American Economic Review, 97 (4): 13051320.

Spier, Kathryn E. and Michael D. Whinston. 1995. "On the efficiency of privately stipulated damages for breach of contracts: entry barriers, reliance, and renegotiation." Rand 
Journal of Economics 26 (2): 180-202.

Wilson, Robert B. 1993. Nonlinear pricing, Oxford, Oxford University Press.

Whinston, Michael D. 2008. Lectures on antitrust economics, Cambridge, MA: MIT Press.

Wright, Julian. 2009. "Exclusive Dealing and Entry, When Buyers Compete: Comment." American Economic Review, 99 (3): 1070-81.

Wright, Joshua D. 2011. "Does antitrust enforcement in high tech markets benefits consumers? Stock price evidence from FTC v. Intel." Review of Industrial Organization 38 (4): $387-404$.

\section{APPENDIX}

This Appendix illustrates the derivation of the baseline model's equilibrium. As noted in the main text, the competitive fringe always prices at cost (i.e., $P_{B}\left(q_{B}\right)=c q_{B}$ ), without imposing any exclusivity clause. Therefore, we can focus on the dominant firm's optimal pricing strategy. We first analyse the equilibrium with non-linear pricing, and then with exclusive contracts.

Non-linear pricing. The firm maximises its profit $\int_{\theta_{\min }}^{\theta_{\max }} P_{A}\left(q_{A}(\theta)\right) f(\theta) d \theta$, where $q_{A}(\theta)$ is chosen by the buyer so as to maximise his net payoff. (Our assumptions guarantee that this maximisation problem is well defined and has a unique solution.) By invoking the Revelation Principle, we can reformulate the problem as if the firm could control $q_{A}(\theta)$ directly (i.e. a direct mechanism). Define the indirect payoff function

$$
v\left(q_{A}, \theta\right)=\max _{q_{B} \geq 0}\left[u\left(q_{A}, q_{B}, \theta\right)-c q_{B}\right],
$$

and use the change of variables $U(\theta)=v\left(q_{A}(\theta), \theta\right)-P_{A}\left(q_{A}(\theta)\right)$. The firm's objective function then becomes

$$
\int_{\tilde{\theta}}^{\theta_{\max }}\left[v\left(q_{A}(\theta), \theta\right)-U(\theta)\right] f(\theta) d \theta
$$

where $\tilde{\theta} \geq \theta_{\min }$ is the lowest type served by the firm (chosen optimally). Provided that the indirect payoff function satisfies the single-crossing condition $v_{\theta q_{A}}\left(q_{A}, \theta\right) \geq 0$ (this is verified in the proof of Proposition 1), the incentive compatibility constraint $q_{A}(\theta)=$ $\arg \max _{q_{A} \geq 0}\left[v\left(q_{A}, \theta\right)-P_{A}\left(q_{A}\right)\right]$ is equivalent to the requirements that $U^{\prime}(\theta)=v_{\theta}\left(q_{A}, \theta\right)$ and that $q_{A}(\theta)$ is non-decreasing. The participation constraint is $U(\theta) \geq v(0, \theta)$, and hence is type dependent. The program then becomes

$$
\begin{aligned}
& \max _{q_{A}(\theta)} \int_{\tilde{\theta}}^{\theta_{\max }}\left[v\left(q_{A}(\theta), \theta\right)-U(\theta)\right] f(\theta) d \theta \\
\text { s.t. } \frac{d U}{d \theta}= & v_{\theta}\left(q_{A}(\theta), \theta\right) \\
U(\theta) \geq & v(0, \theta)
\end{aligned}
$$


and $q_{A}(\theta)$ non-decreasing. This is an optimal control program with $q_{A}(\theta)$ as the control variable and $U(\theta)$ as the state variable. Once the optimal quantity has been found, one can then recover the tariff that supports it.

By a standard integration by parts, the firm's problem can be rewritten as

$$
\max _{q_{A}(\theta)} \int_{\tilde{\theta}}^{\theta_{\max }}\left[v\left(q_{A}(\theta), \theta\right)-\frac{1-F(\theta)}{f(\theta)} v_{\theta}\left(q_{A}, \theta\right)\right] f(\theta) d \theta,
$$

where the term inside square brackets is usually referred to as the "virtual surplus."

In what follows, we shall impose some regularity conditions that serve to simplify the analysis. The first is:

H1. For all values of $c$, the virtual surplus function

$$
v\left(q_{A}, \theta\right)-\frac{1-F(\theta)}{f(\theta)} v_{\theta}\left(q_{A}, \theta\right)
$$

is globally concave in $q_{A}$ and has increasing differences in $q_{A}$ and $\theta$.

This assumption guarantees that the solution to the dominant firm's problem can be found by pointwise maximisation of the virtual surplus function. If it fails, an ironing procedure is needed, and the solution exhibits bunching. The condition can be reformulated in terms of the primitives of the model, but this involves third derivatives, the economic interpretation of which is not obvious. However, it is easily met in the uniform-quadratic specification (this is true, in fact, for all the regularity conditions that we shall introduce).

As with the indirect payoff function, the virtual surplus function has two branches corresponding to the cases in which the quantity

$$
\tilde{q}_{B}\left(q_{A}, \theta\right)=\arg \max _{q_{B} \geq 0}\left[u\left(q_{A}, q_{B}, \theta\right)-c q_{B}\right]
$$

is 0 or is strictly positive, and a kink in between. The maximum may occur along either branches, or at the kink. When the maximum occurs along the branch with $\tilde{q}_{B}\left(q_{A}, \theta\right)=$ 0 , it is the monopoly solution $q^{m}(\theta)$. When the maximum occurs along the branch corresponding to $\tilde{q}_{B}\left(q_{A}, \theta\right)>0$, we obtain the common representation outcome $q_{A}^{c r}(\theta)$ (this may be a slight misuse of terminology as $q_{A}^{c r}(\theta)$ could in fact be nil.) As for the kink, it is implicitly defined by the condition $u_{q_{B}}\left(q_{A}(\theta), 0, \theta\right)=c$, which coincides with condition (3) in the main text. Therefore, this is the limit pricing solution $q^{\lim }(\theta)$.

To reduce the number of cases that need to be taken into consideration, we rule out multiple intersections between the curve $q^{\lim }(\theta)$ and the curves $q^{m}(\theta)$ and $q_{A}^{c r}(\theta)$.

H2. The curves $q^{m}(\theta)$ and $q^{\lim }(\theta)$, and the curves $q^{\lim }(\theta)$ and $q_{A}^{c r}(\theta)$, intersect at most once.

Under H1 and H2, Proposition 1 holds. The proof may be found in the online Appendix.

Exclusive contracts. When exclusive contracts are permitted, the dominant firm can control not only $q_{A}(\theta)$, but also whether $q_{B}(\theta)$ may be positive or must be nil. In general, 
the firm can set $q_{B}(\theta)$ to nil (i.e. impose an exclusivity clause) in some states of demand, and allow $q_{B}(\theta)$ to be positive for others. However, it is convenient to first consider the firm's optimal pricing when constrained to offer only non-exclusive contracts, next consider the firm's optimal pricing when constrained to offer only exclusive contracts, and then to address how the firm should combine these two.

When the dominant firm is constrained to offer only non-exclusive contracts, the problem it faces is identical to (A.1), since in the competitive fringe model $P_{B}^{E}\left(q_{B}\right)=$ $P_{B}^{N E}\left(q_{B}\right)=c q_{B}$. The solution, which has been characterised in Proposition 1, is denoted by $q_{A}^{N E}(\theta)$.

Next consider the program in which the firm imposes an exclusivity clause on all buyers. Since $q_{B}(\theta)$ is thereby set to zero, the firm's problem is

$$
\begin{aligned}
& \max _{q_{A}(\theta)} \int_{\tilde{\theta}}^{\theta_{\max }}\left[u\left(q_{A}(\theta), 0, \theta\right)-U(\theta)\right] f(\theta) d \theta \\
\text { s.t. } \frac{d U}{d \theta}= & u_{\theta}\left(q_{A}(\theta), 0, \theta\right) \\
U(\theta) \geq & v(0, \theta)
\end{aligned}
$$

and $q_{A}(\theta)$ non-decreasing. We use $q_{A}^{E}(\theta)$ to denote the solution to problem (A.2).

Compared with problem (A.1), the indirect payoff function $v\left(q_{A}(\theta), \theta\right)$ is replaced by $u\left(q_{A}(\theta), 0, \theta\right)$. (Note that the regularity condition H1 applies to $u\left(q_{A}(\theta), 0, \theta\right)$ as well, since $v\left(q_{A}(\theta), \theta\right)=u\left(q_{A}(\theta), 0, \theta\right)$ when $c$ is large enough.) If the monopoly tariff lies below the $c q$ line, the dominant firm can implement the monopoly solution $q^{m}(\theta)$. In this case, the participation constraint $U(\theta) \geq v(0, \theta)$ in problem (A.2) is non-binding. Otherwise, the dominant firm must undercut the competitive fringe, pricing at $P^{E}=c q$ and selling $q^{e}(\theta)$ units of its product.

Again, to reduce the number of cases to be considered, we rule out multiple intersections between the relevant curves.

H3. The curves $q^{m}(\theta)$ and $q^{e}(\theta)$ intersect at most once.

Note that $q^{m}\left(\theta_{\max }\right)>q^{e}\left(\theta_{\max }\right)$ as a result of the no-distortion-at-the-top property. Therefore, if the curves do intersect, the curve $q^{e}(\theta)$ must cut $q^{m}(\theta)$ from above. It follows that the solution to problem (A.2) may either coincide with $q^{m}(\theta)$, or it may be formed by two branches, i.e. $q^{e}(\theta)$ for low types and $q^{m}(\theta)$ for high types. Clearly, the first pattern will emerge if the dominant firm's competitive advantage is large enough.

In general, however, the dominant firm may want to impose exclusivity dealing on subsets of buyers only. Therefore, it must solve a hybrid screening problem with one continuous variable (i.e. $q_{A}(\theta)$ ) and one discrete variable (i.e. whether $q_{B}(\theta)$ can be positive or must be nil). This translates into a multi-stage optimal control problem involving two different control systems, (A.1) and (A.2), and the possibility of switching from one system to the other. To solve this problem, one needs to choose a sequence of control systems, the switching points, and the control function $q_{A}(\theta)$ for each system 
that maximise the firm's profit. ${ }^{50}$

Generally speaking, the solution for each control system may depend on the number and order of the switches. However, in Calzolari and Denicolò (2015) we prove the following separation property: for any possible sequence of control systems and switching points, the optimal control function for our multi-stage problem coincides with $q_{A}^{N E}(\theta)$ whenever problem (A.1) applies, and with $q_{A}^{E}(\theta)$ whenever problem (A.2) applies. The separation property requires only mild regularity conditions (to be precise, that $q_{A}^{N E}(\theta)$ and $q_{A}^{E}(\theta)$ are strictly increasing and that the participation constraint is only binding for the lowest types) which are met in our problem. The separation property guarantees that the solution to the multistage problem is either $q_{A}^{N E}(\theta)$ or $q_{A}^{E}(\theta)$.

Our last simplifying assumption guarantees that the solution to the multi-stage control problem involves a unique switch which, as explained in the body of the paper, must necessarily be a switch from exclusive to non-exclusive dealing.

H4. $v_{\theta}\left(q_{A}^{N E}(\theta), \theta\right)>u_{\theta}\left(q_{A}^{E}(\theta), 0, \theta\right)$.

In specific examples, such as the uniform-quadratic model, it is easy to verify that H4 holds. More generally, $\mathrm{H} 4$ will hold if, for example, $u_{\theta q_{i}}$ is constant provided that aggregate sales are greater under non exclusivity than under exclusivity.

Under H1-H4, Proposition 2 holds. The proof may be found in the online Appendix.

\footnotetext{
${ }^{50}$ This complication does not arise in the symmetric framework of Calzolari and Denicolò (2013). In that case, the structure of equilibrium exclusive contracts is fully pinned down by competitive forces, since competition in utility space is fierce. When, on the other hand, the dominant firm enjoys a large competitive advantage, and thus is totally or partially sheltered from rivals in utility space, it has room for designing its exclusive contracts so as to better screen the buyers.
} 